\title{
Heme oxygenase-1 promotes granuloma development and protects against dissemination of mycobacteria
}

\author{
Doron Regev ${ }^{1}$, Ranu Surolia ${ }^{2}$, Suman Karki², Jason Zolak², Ana Montes- Worboyss ${ }^{3}$, Ocatvio Oliva², \\ Purushotum Guroji ${ }^{2}$, Vikram Saini ${ }^{4}$, Adrie JC Steyn ${ }^{4,5}$, Anupam Agarwal ${ }^{6}$ and Veena B Antony ${ }^{1,2}$
}

Non-tuberculous mycobacterial (NTM) infections occur in both immunocompromised and immunocompetent hosts and are an increasingly recognized cause of morbidity and mortality. The hallmark of pulmonary mycobacterial infections is the formation of granuloma in the lung. Our study focuses on the role of heme oxygenase-1 (HO-1), a cytoprotective enzyme, in the regulation of granuloma development and maturation following infection with Mycobacterium avium. We examined the role of HO-1 in regulating monocyte chemoattractant protein-1 (MCP-1) and chemokine receptor 2 (CCR2), two molecules involved in monocyte-macrophage cell trafficking after infection. We showed that RAW 264.7 mouse monocytes exposed to M. avium expressed HO-1 and MCP-1. Inhibition of HO by zinc protoporphyrin-IX led to inhibition of MCP-1 and increased expression of CCR2, its cognate receptor. HO-1 ${ }^{-1-}$ mice did not develop organized granuloma in their lungs, had higher lung colony forming unit of $M$. avium when infected with intratracheal M. avium, and had loose collections of inflammatory cells in the lung parenchyma. Mycobacteria were found only inside defined granulomas but not outside granuloma in the lungs of $\mathrm{HO}-1^{+/+}$mice. In $\mathrm{HO}-1^{-/-}$mice, mycobacteria were also found in the liver and spleen and showed increased mortality. Peripheral blood monocytes isolated from GFP ${ }^{+}$mice and given intravenously to $\mathrm{HO}-1^{+/+}$mice localized into tight granulomas, while in $\mathrm{HO}-1^{-/-}$mice they remained diffusely scattered in areas of parenchymal inflammation. Higher MCP-1 levels were found in bronchoalveolar lavage fluid of $M$. avium infected $\mathrm{HO}-1^{-/-}$mice and CCR2 expression was higher in $\mathrm{HO}-1^{-/-}$alveolar macrophages when compared with $\mathrm{HO}-1^{+/+}$ mice. CCR2 expression localized to granuloma in $\mathrm{HO}-1^{+/+}$mice but not in the $\mathrm{HO}-1^{-/-}$mice. These findings strongly suggest that $\mathrm{HO}-1$ plays a protective role in the control of $M$. avium infection.

Laboratory Investigation (2012) 92, 1541-1552; doi:10.1038/labinvest.2012.125; published online 10 September 2012

KEYWORDS: chemoattractant protein-1 (MCP-1); chemokine receptor 2 (CCR2); disseminated lung infection; granuloma; heme oxygenase-1 (HO-1); Mycobacterium avium

Non-tuberculous mycobacterial (NTM) infection is a growing problem in the United States and remains poorly diagnosed in developing countries. An increase in NTM infections has been observed in the Southeastern United States. ${ }^{1-5}$ Disseminated mycobacterial infection is one of the major causes of morbidity and mortality in patients who are immunocompromised such as those with HIV and AIDS. Recently, there has been an increase in pulmonary NTM infections in immunocompetent patients; mostly in older women and in patients with cystic fibrosis. ${ }^{1,2}$
Mycobacterium avium (M. avium) is a NTM that can cause infection in patients with underlying conditions that compromise local lung or systemic immunity. It is increasingly recognized as a major human pathogen, primarily following the emergence of the AIDS epidemic. ${ }^{6}$ A hallmark of disseminated $M$. avium infections is the presence of mycobacteria in multiple organs including the liver, spleen, lymph nodes, bone marrow, and lung. ${ }^{1,3,6}$ Granulomas are formed as a consequence of chronic antigen persistence and their formation involves the interaction between the infectious

\footnotetext{
${ }^{1}$ Division of Pulmonary, Critical Care and Sleep Medicine, College of Medicine, University of Florida, Gainesville, FL, USA; ${ }^{2}$ Division of Pulmonary and Critical Care Medicine, Department of Medicine, University of Alabama at Birmingham, Birmingham, AL, USA; ${ }^{3}$ Unidad Médico-Quirúrgica de Enfermedades Respiratorias, Instituto de Biomedicina de Sevilla (IBiS), Hospital Universitario Virgen del Rocío, Sevilla, Spain; ${ }^{4}$ Department of Microbiology, University of Alabama at Birmingham, Birmingham, AL, USA; ${ }^{5}$ KwaZulu-Natal Research Institute for TB and HIV, Durban, South Africa and ${ }^{6}$ Division of Nephrology, Department of Medicine, University of Alabama at Birmingham, Birmingham, AL, USA

Correspondence: Professor VB Antony, MD, Department of Medicine, University of Alabama at Birmingham, 1530, 3rd Avenue South, THT 422, Birmingham, AL 35294-
} 0006, USA.

E-mail: veena.antony@ccc.uab.edu

Received 28 May 2012; revised 11 July 2012; accepted 25 July 2012 
organism and host immune cells, including macrophages, and $\mathrm{T}$ cells, as well as immune effectors such as chemokines and cytokines. ${ }^{6,7}$ Mature granulomas include fibroblasts and extracellular matrix, which surround and isolate the granulomas from other tissues. ${ }^{8}$ Importantly, organisms are not always eliminated from the granuloma, but can become dormant, resulting in latent infection. ${ }^{9}$

Heme oxygenase-1 (HO-1) is a cytoprotective enzyme that breaks down heme to produce carbon monoxide, iron, and biliverdin. ${ }^{10} \mathrm{HO}-1$ is induced by multiple stimuli including oxidative stress, pro-inflammatory cytokines and has been shown to be upregulated in lungs following mycobacterial infection. ${ }^{10-12}$ While HO-1-derived carbon monoxide can induce the DosR dormancy regulon in mycobacteria leading to latency and survival of the organism inside host granuloma, ${ }^{13}$ it is not clear whether $\mathrm{HO}-1$ regulates the key host response of granuloma formation. Monocyte chemotactic protein-1 (MCP-1/CCL2), a C-C chemokine, along with its receptor chemokine receptor 2 (CCR2) on monocytes-macrophages is responsible for the recruitment of mononuclear cells from peripheral blood to sites of inflammation. ${ }^{14,15}$ However, a link between $M$. avium induced granuloma formation and HO-1 has not yet been established.

We evaluated the regulatory role of HO-1 in the recruitment of monocyte-macrophages and found that the activation of the MCP-1/CCR2 axis by M. avium infection was impaired by inhibition of $\mathrm{HO}$ activity. $\mathrm{HO}-1^{+/+}$mice showed mature, organized granuloma formation in lung tissue following M. avium infection without dissemination. In contrast, HO-1 ${ }^{-1-}$ mice had diffused, unorganized collections of mononuclear cells in the lungs with mycobacteria in the spleen and liver as evidence of dissemination of infection.

\section{MATERIALS AND METHODS Mouse Monocyte Culture}

RAW 264.7 cells were obtained from American Type Culture Collection (Manassas, VA, USA) and maintained in Dulbecco's Modified Eagle's Medium as previously described. ${ }^{16}$

\section{Treatment of RAW 264.7 Cells with M. avium and Zinc Protoporphyrin-IX (ZnPP-IX)}

Cells were plated on $60 \mathrm{~mm}$ culture dishes (Corning, Lowell, MA, USA) at a concentration of $1 \times 10^{6}$ cells and treated with M. avium $\left(50 \times 10^{6}\right.$ bacteria per plate $)$ in serum-free medium (SFM). Alternatively, cells were pretreated with $10 \mu \mathrm{M}$ ZnPPIX (Frontier Scientific, Logan, UT, USA) for $30 \mathrm{~min}$ in SFM and incubated at $37^{\circ} \mathrm{C}$ for different time points.

\section{Quantitative PCR Analysis}

Total RNA from cultured cells was purified by a commercial kit (RNeasy Mini Kit, Qiagen Science, MD, USA). The quantitative analysis of MCP-1 and CCR2 receptor genes were assessed by PCR as described. ${ }^{17,18}$ The mRNA levels of HO-1, MCP-1, and CCR2 were quantified using the mouse HO-1 forward-5'-CACGCATATACCCGCTACCT-3', reverse- $5^{\prime}$ -
AAGGCGGTCTTAGCCTCTTC-3'; mouse MCP-1 forward5'-GGCTCAGCCAGATGCAGTTAA- ${ }^{\prime}$, reverse- $5^{\prime}$ CCTACT CATTGGGATCATCTTGCT- $3^{\prime}$; and mouse CCR2 forward5'-CAACTCCTTCATCAGGCACAR- $3^{\prime}$, reverse- $5^{\prime}$-GGAAAGAGGCAGTTTGCAAAG-3', respectively.

\section{HO-1 Knockout Mouse Model}

We used the HO-1 ${ }^{-1-}$ mice generated by Poss and Tonegawa, and Kapturczak et al. ${ }^{19,20}$ Age-matched wild-type $\left(\mathrm{HO}-1^{+/+}\right)$littermates were used as controls. The protocol was approved by the Institutional Animal Care and Use Committee (IACUC) at the University of Florida.

\section{Mouse Model of M. avium Infection}

M. avium subspecies avium Chester (ATCC\# 15769) was maintained in ATCC medium 90 Lowenstein Jenson medium and grown in Lowenstein-Jensen Medium Slants (BD Biosciences, San Jose, CA, USA) according to the manufacturer's instructions. $\mathrm{HO}-1^{+1+}$ and $\mathrm{HO}-1^{-1-}$ mice were infected with $1 \times 10^{7} \mathrm{M}$. avium cells in PBS via intratracheal route once per week for 3 weeks. An additional group of wild-type $\left(\mathrm{HO}-1^{+/+}\right)$control mice were inoculated with equal volume of PBS. After 6 months, the mice were euthanized and lung tissue was harvested. Tissue was fixed in $4 \%$ paraformaldehyde at room temperature for $24 \mathrm{~h}$ and processed for immunohistochemistry.

\section{Determination of Mycobacterial Colony Forming Units (CFU) in the Lung}

To assess mycobacterial growth, the lungs were removed aseptically at specified time points. The lungs were cut into small pieces, and homogenized. Viable mycobacteria in the lung homogenates were then assessed as CFU by performing serial dilutions from the lung homogenate and plating onto 7H11 agar in six-well plates in duplicates. The plates were incubated under $100 \%$ humidity, $5 \% \mathrm{CO}_{2}$, at $37^{\circ} \mathrm{C}$ for $2-3$ weeks, and colonies were counted. The plates were again incubated for an additional 2 weeks to decrease the possibility of failure to detect slower growing $M$. avium strains. No difference in the number of colonies was observed in re-incubated plates.

\section{Estimation of HO-1 Protein by Western Blot Analysis}

Lung tissues were weighed and lysed in RIPA buffer and $20 \mu \mathrm{g}$ of total proteins were resolved by SDS-polyacrylamide gel electrophoresis and transferred to a nitrocellulose membrane. Proteins were detected with antibodies against HO-1 (1:1000), and $\beta$-actin (1:2000) (Santa Cruz Biotechnology, CA, USA). Blotted antibody was developed by horseradish peroxidase-conjugated secondary antibody and enhanced chemiluminescence detection system. $\beta$-Actin was probed as an internal loading control. 


\section{Quantitative Morphometric Examination}

The effect of $M$. avium infection on pleural macrophage recruitment and granuloma formation as measured by the number and size of granuloma on the pleural surface and monocyte infiltration in the submesothelial area on light microscopy morphometric examinations. A quantitative method was used to evaluate the number and size of granuloma on gross pathology as well as light microscopy. Following sacrifice of the animal, the chest cavity was opened and the image captured onto a Macintosh computer screen. Imaging data for granuloma is expressed as number of granuloma $/ \mathrm{mm}^{2}$. The lung section were fixed and stained with hematoxylin and eosin. A bar grid scale set at $1-1000$ p.r.m. is superimposed on the photomicrograph to permit quantification of numbers of macrophages and size of granuloma. Areas were randomly selected and include a maximum of 10 grids. The light microscopic images were captured onto the computer screen via an Olympus MT-2 microscope.

\section{Tracking GFP ${ }^{+}$Monocytes in HO-1 ${ }^{++}$and HO-1 ${ }^{-1-}$ Mice Infected with $M$. avium}

Peripheral blood monocytes from GFP-transgenic C57BL/6 mice (monocytes in these mice constitutively express GFP) were isolated by density gradient centrifugation and incubated with serum-free media with either IL-2 (200 units/ml based on preliminary observation), or IFN- $\gamma(500 \mathrm{U} / \mathrm{ml})$. In all, $3 \times 10^{6}$ PBMC were inoculated intravenously via caudal vein into $\mathrm{HO}-1^{-1-}$ mice with established pulmonary parenchymal infection by $M$. avium. The mice were euthanized after $24 \mathrm{~h}$ and the lungs were perfused with heparinized Hanks' Balanced Salt Solution (HBSS). The lungs were flash frozen in OCT compound and $4 \mu \mathrm{m}$ thick sections were sectioned. The sections were viewed under a fluorescence microscope at 465 excitation and 535 emission spectra (Zeiss Axiovert 200M) to localize the GFP-positive monocytes in the lung section. The granuloma formation, bacterial clearance, and mortality were estimated as previously described. ${ }^{21}$

\section{MCP-1 Expression by ELISA}

Mouse whole blood was collected through the abdominal aorta using a 25-gauge needle, centrifuged, aliquoted, and stored at $-80^{\circ} \mathrm{C}$. Bronchoalveolar lavage fluid (BALF) was collected by ligating a catheter into the airway using thread and injecting 800-1000 $\mu \mathrm{l}$ of (HBSS) into the lung. The BALF was centrifuged, the supernatant was aliquoted and stored at $-80^{\circ} \mathrm{C}$, and the BALF pulmonary alveolar macrophages (PAM) were collected for flow cytometry studies for analysis of CCR2 receptor expression. Supernatants were tested for MCP-1 using ELISA (R\&D Systems, Minneapolis MN, USA).

\section{CCR2 Expression by Flow Cytometry}

PBMC were isolated by density gradient centrifugation, and SFM with either IL-2 (200 units $/ \mathrm{ml}$ based on preliminary observation), or IFN- $\gamma(500 \mathrm{U} / \mathrm{ml}$ based on previously published (59) work) for $2-48 \mathrm{~h}$ at $37^{\circ} \mathrm{C}$ in $5 \% \mathrm{CO}_{2}$ atmosphere. The PBMC were washed three times in PBS with 5\% BSA and $5 \mathrm{mM}$ sodium azide and incubated for $45 \mathrm{~min}$ at $4{ }^{\circ} \mathrm{C}$ in either the presence of rabbit anti-mouse CCR2 $(1 \mu \mathrm{g} /$ $10^{6}$ cells) monoclonal antibody or isotype $\mathrm{Ab}$ (IgG1). Cells were washed three times and labeled with goat anti-rabbit IgG1 FITC-conjugate to detect the antibody bound to the antigens. After incubations, the cells were washed three times and fixed in $4 \%$ paraformaldehyde. The fluorescence associated with the PBMC's and PAM were analyzed by flow cytometry using a FACS star (Becton-Dickinson Immunocytometry Systems, Mountain View, CA, USA). Fluorescence data were collected on log scale and the relative fluorescence intensity was reported by comparing their light scatter characteristics to those of normal cells analyzed in the same experiment.

\section{Immunohistochemistry}

Paraffin-embedded tissues were stained with hematoxylin and eosin (H\&E). Sections were stained for CCR2 using anti mouse primary antibody (Capralogics, Hardwick, MA, USA) and $\mathrm{ABC}$ staining kit (Vector Laboratories, Burlingame, CA, USA) according to the manufacturer's recommendations. Alternatively, sections were stained with primary antibody for HO-1 (Calbiochem, San Diego, CA, USA). Sections were also stained with TB Fluorescent Stain Kit M (BD Biosciences, Sparks, MD, USA) to visualize M. avium in lung tissue.

\section{Statistical Analysis}

Data were analyzed by the unpaired Student's $t$-test using Statview software version 5.0, SAS Inst. (Cary, NC, USA). All experiments were done in triplicate. Differences were considered significant at $P<0.05$ level.

\section{RESULTS}

\section{M. avium Induces HO-1 Expression}

To address the role of $\mathrm{HO}-1$ in $M$. avium infection, we exposed RAW 264.7 cells to $M$. avium at 50 multiplicity of infection (MOI). One day after infection, the cells were fixed and stained for HO-1. HO-1 was induced following $24 \mathrm{~h}$ infection with $M$. avium as compared with untreated cells (Figure 1a and b). To substantiate the above observation, we analyzed mRNA levels of HO-1 in RAW 264.7 cells treated with $M$. avium or untreated as previously described in the Methods section. Real-time PCR results showed that HO-1 relative gene expression was significantly increased in a timedependent manner in RAW 264.7 cells following M. avium treatment (Figure 1c).

\section{MCP-1 Levels Increase in RAW 264.7 Cells Treated with M. avium}

In order to test the relationship between HO-1 and MCP-1, RAW 264.7 cells were pretreated with $10 \mu \mathrm{M}$ ZnPP-IX, a competitive inhibitor of $\mathrm{HO}$ enzymatic activity for $30 \mathrm{~min}$ and then incubated with M. avium or SFM. After 4, 8, and 

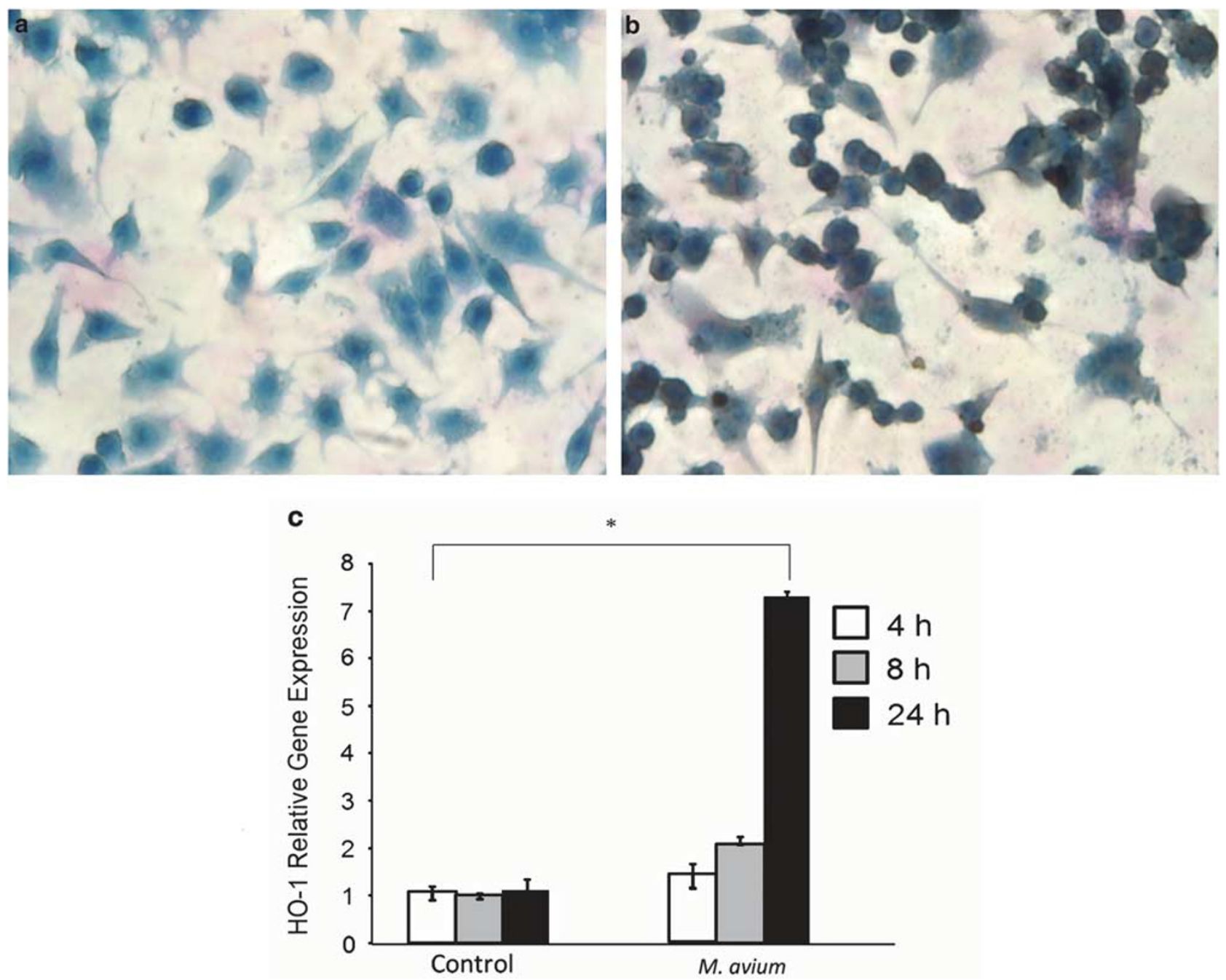

Figure 1 M. avium infection induces HO-1 in RAW 264.7 monocyte-macrophages. (a, b) Representative light micrograph showing immunocytochemical detection of HO-1 in RAW 264.7. Panel (a) shows the control cells were incubated in SFM while panel (b) shows the cells infected with M. avium $(50 \mathrm{MOI})$ for $24 \mathrm{~h}$. Cells were fixed and stained with anti-HO-1 antibody and visualized by optical microscopy at $\times 400$ magnification. The infected cells stained for HO-1 expression (brown) after $24 \mathrm{~h}$ as compared with control cells. Blue color shows counter-stain with hematoxylin. The photomicrograph is the representative of three individual staining. (c) HO-1 relative mRNA expression significantly increases in RAW 264.7 cells after infection with M. avium. Control cells were incubated in SFM and treated cells were incubated with M. avium. For 4, 8, and 24h, HO-1 relative gene expression was analyzed by RT-PCR. HO-1 levels significantly increased in cells treated with $M$. avium as compared with non-treated cells in a time-dependent manner $\left({ }^{*} P<0.001\right)$. Values represent the mean of three different experiments.

$24 \mathrm{~h}$ of incubation, cells were harvested and mRNA levels of $M C P-1$ were analyzed by RT-PCR. MCP-1 protein levels were also measured in the supernatant of treated and control cells. We found that $M C P-1$ mRNA levels were significantly increased in a time-dependent manner when cells were treated with M. avium as compared with untreated cells (Figure 2a). However, as expected, these levels decreased significantly when we pretreated the cells with the HO inhibitor ZnPP-IX (Figure 2a).

\section{CCR2 mRNA Expression is Increased in RAW 264.7 Cells After Pretreatment with ZnPP-IX}

To determine whether $M$. avium infection and $\mathrm{HO}$ inhibition affect gene expression of CCR2, mRNA levels of CCR2 were measured in RAW 264.7 cells following the same protocol as explained above. Our results indicated that CCR2 gene expression was significantly increased following pretreatment with ZnPP-IX and M. avium infection. However, no significant increase in CCR2 gene expression was found in cells treated with $M$. avium as compared with non-treated cells (Figure 2b).

\section{HO-1 ${ }^{-I-}$ Mice Failed to Form Mature, Organized Granulomas Following $M$. avium Infection}

Our in vitro results suggested that $\mathrm{HO}-1$ appeared to play a role in the regulation of both MCP-1 and CCR2 following infection with $M$. avium. To evaluate the role of HO-1 in granuloma formation in vivo, we used a mouse model of HO-1 deficiency and compared granuloma formation in HO- 

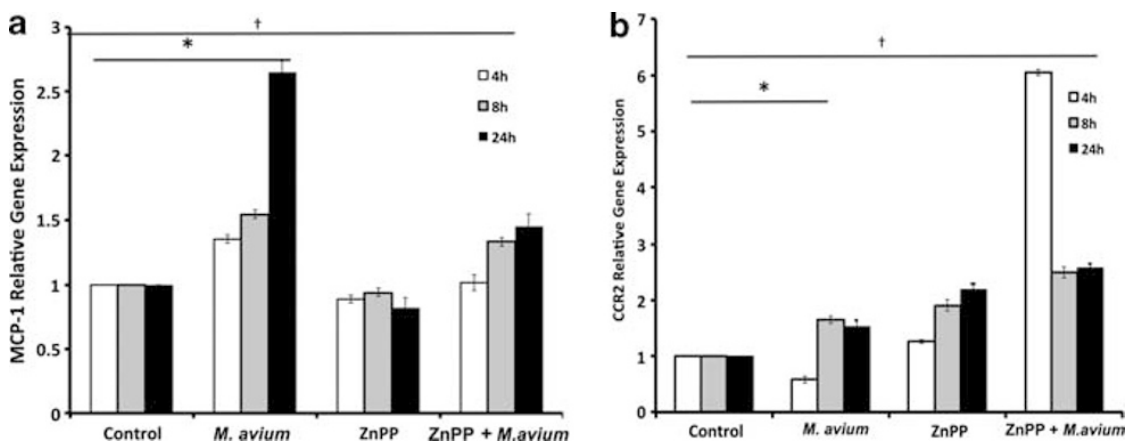

Figure $2 \mathrm{HO}$ inhibition decreases MCP-1 while increase CCR2 relative gene expression in vitro following the infection by M. avium. RAW 264.7 cells were pretreated with SFM (control) or ZnPP-IX (HO inhibitor) for $30 \mathrm{~min}$ and then incubated with M. avium for 4, 8, and $24 \mathrm{~h}$. MCP-1 and CCR2 relative gene expression was analyzed by RT-PCR. (a) MCP-1 levels were higher in $M$. avium-treated cells as compared with controls $\left({ }^{*} P<0.001\right)$ and were significantly downregulated ( $(\mathrm{P}<0.001)$ when cells were pretreated with ZnPP-IX, for 8 and $24 \mathrm{~h}$ as compared with $M$. avium alone for the same time points. No significant differences were observed at the 4-h time point. Values represent the mean of three different experiments. (b) CCR2 gene expression was significantly increased as compared with controls at all time points $\left({ }^{*} P<0.05\right)$. CCR2 relative gene expression was higher in cells pretreated with ZnPP-IX as compared with cells treated with $M$. avium alone $\left({ }^{\dagger} P<0.05\right)$. Values represent the mean of three different experiments.

$1^{+/+}$mice and $\mathrm{HO}-1^{-1-}$ mice following $M$. avium infection. We examined the lungs of $\mathrm{HO}-1^{+1+}$ and $\mathrm{HO}-1^{-1-}$ mice, 6 weeks, 16 weeks, and at 6 months post M. avium infection and compared the results with lungs from control mice inoculated with saline at the same time period. We examined the lungs of $\mathrm{HO}-1^{+/+}$and $\mathrm{HO}-1^{-/-}$mice 6 months after $M$. avium infection and compared the results with lungs from control mice inoculated with saline at the same time period. At the end of the experimental period, mice were euthanized and the lungs, spleen, and liver were harvested for analysis. Lungs from $\mathrm{HO}-1^{+1+}$ infected mice showed organized, mature granulomas whereas, lungs from $\mathrm{HO}-1^{-1-}$ infected mice presented unorganized, loose collections of mononuclear cells (Figure $3 \mathrm{~b}$ and $\mathrm{d}$ ).

To confirm granuloma formation, we analyzed H\&Estained lung sections from the same mice. As shown in Figure $3 \mathrm{e}-\mathrm{h}$, it was clear that $\mathrm{HO}-1^{+/+}$infected mice developed organized granulomas as compared with $\mathrm{HO}-1^{-1-}$ mice, which displayed loose, unorganized lesions in the lungs after exposure to M. avium. We used $\mathrm{HO}-1^{+1+}$ and $\mathrm{HO}-1^{-l_{-}}$ mice inoculated with saline as a negative control for $M$. avium infection and observed no significant damage in lung tissue and no histological presence of granulomas (Figure $3 \mathrm{a}, \mathrm{c}, \mathrm{e}$, and $\mathrm{g}$ ). The inability of $\mathrm{HO}-1^{-1-}$ mice to form mature, organized granulomas led to disseminated infection with more inflammation and lesions covering a greater area of the lungs (Figure $3 \mathrm{~d}$ and $\mathrm{h}$ ). Disseminated infection was also evident in infected $\mathrm{HO}-1^{-1}$ mice, which presented diffuse collections of mononuclear cells as well as positive cultures for M. avium in the liver and spleen and displayed increased mortality (Table 1 ).

\section{HO-1 ${ }^{-I-}$ Mice Failed to Form Mature, Organized Granulomas with Dispersed $M$. avium in Lung Tissue}

Using the TB auramine stain M (BD Biosciences, Sparks, $\mathrm{MD}$, USA), we were able to visualize fluorescently labeled $M$. avium in mouse lung tissue and in individual cells.
We compared our H\&E-stained tissue (Figure $4 \mathrm{~d}-\mathrm{f}$ ) with the corresponding Auramine-stained tissue (Figure $4 a-c)$. We observed a diffuse presence of mycobacteria in lung tissue in HO- $1^{-1-}$ mice following infection (Figure $4 \mathrm{c}$ and $\mathrm{f}$ ). However, mycobacteria were contained inside mature granulomas in $\mathrm{HO}-1^{+/+}$mice following infection (Figure $4 \mathrm{~b}$ and e). Saline controls did not show any mycobacteria in lung tissue (Figure $4 \mathrm{a}$ and $\mathrm{d}$ ).

\section{HO-1 ${ }^{+/+}$PBMC (from GFP ${ }^{+}$Mice) Home to the Granuloma in $\mathrm{HO}-1^{+I+}$ but not $\mathrm{HO}-1^{-I-}$ Mice}

In order to evaluate if reconstitution of $\mathrm{HO}-1^{-/-}$mice with HO- $1^{+1+}$ monocytes resulted in the recruitment of $\mathrm{GFP}^{+}$ monocytes to the lung, with increased granuloma formation, increased clearance of mycobacteria and decreased mortality, monocytes were isolated from GFP + transgenic C57BL/6 mice and were inoculated intravenously via caudal vein into HO- $1^{-1-}$ mice with established $M$. avium infection. The GFP-PBMCs were disseminated diffusely in the lung tissue in HO- $1^{-1-}$ mice (Figure $5 \mathrm{c}$ ), pointed with arrows) and not organized into the granuloma at 6 weeks through 6 months. The GFP-PBMCs were disseminated diffusely in the lung tissue in $\mathrm{HO}-1^{-1-}$ mice (Figure $5 \mathrm{c}$ ), pointed with arrows) and not organized into the granuloma. In $\mathrm{HO}-1^{+/+}$mice, the GFP-PBMC were localized into granulomas and were better organized (Figure 5f, pointed with arrow) compared with $\mathrm{HO}-$ $1^{-1-}$ mice. These data demonstrate that in $\mathrm{HO}-1^{+/+}$mice, PBMC were recruited into lung granulomas, suggesting modulates monocyte recruitment into granulomas.

\section{M. avium CFU Counts are Higher in $\mathrm{HO}-1^{-1-}$ Lung Tissue than in $\mathrm{HO}-\mathbf{1}^{+I+}$ Tissue}

To test whether the failure of $\mathrm{HO}-1^{-1-}$ mice to form mature granulomas had any effect on their ability to control and contain the infection, we harvested lung tissue from infected $\mathrm{HO}-1^{+1+}$ and $\mathrm{HO}-1^{-1-}$ mice and counted $\mathrm{CFU}$ in the tissue. M. avium were recovered from liver and spleen culture 


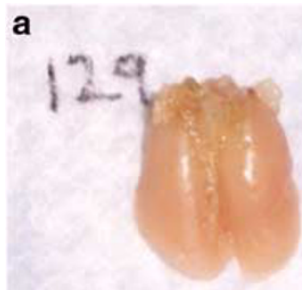

$\mathrm{HO}-1^{+/+}-$Control

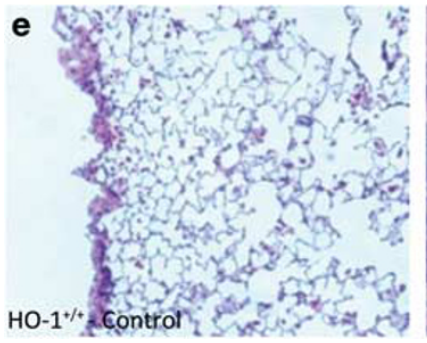

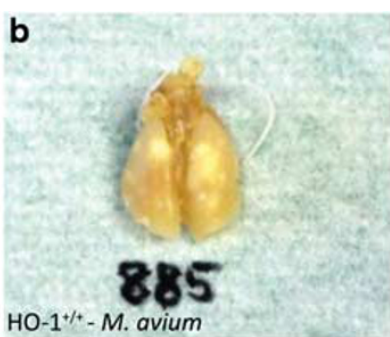

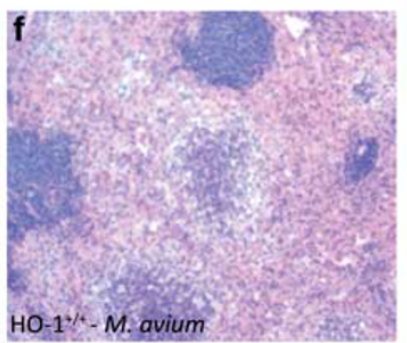

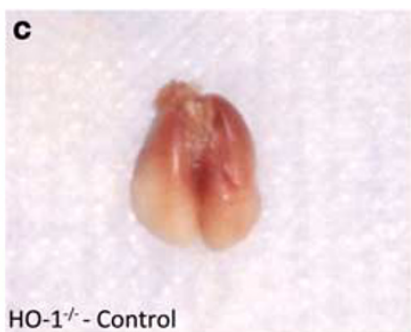
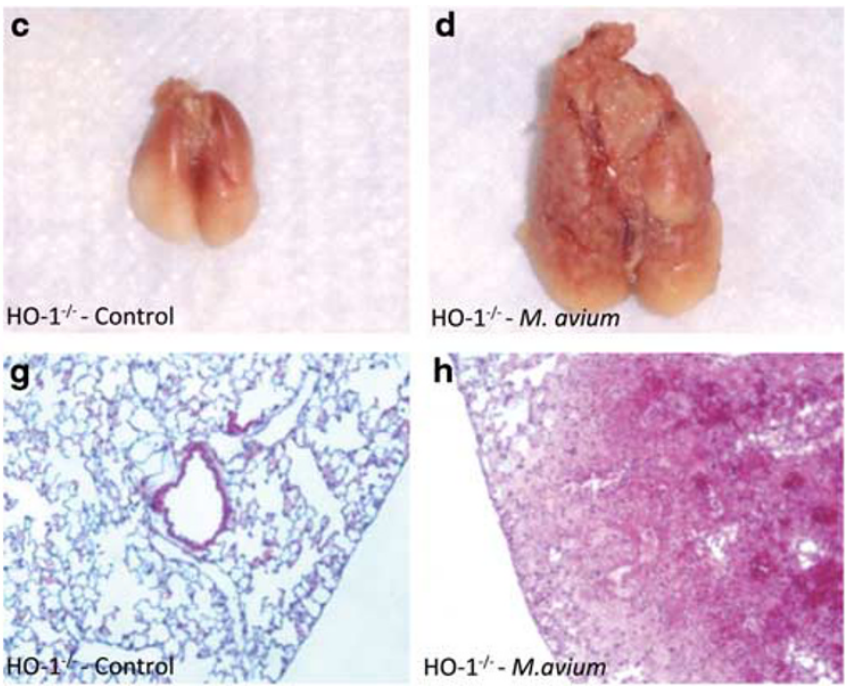

Figure 3 Mouse lung tissue showing differential granuloma formation in $\mathrm{HO}-1^{+/+}$and $\mathrm{HO}-1^{-1-}$ mice after 6 month $M$. avium infection or saline inoculation. Mouse lungs were harvested following 6-month $M$. avium inoculation and visually inspected for the presence of granuloma. Alternatively, the lung tissue was fixed and stained with $\mathrm{H} \& \mathrm{E}$ to confirm granuloma formation. (a) The absence of granuloma in $\mathrm{HO}-1^{+/+}$control lung. (b) The presence of organized, mature granulomas in $\mathrm{HO}-1^{+/+}$lung inoculated with $M$. avium for 6 months. (c) Absence of granuloma in HO- $1^{-} /-$control lung. (d) Diffuse infection and unorganized granuloma formation in $\mathrm{HO}-1^{-1-}$ lung inoculated with $M$. avium for 6 months. (e) $\times 200 \mathrm{H} \& \mathrm{E}$ stain of normal tissue from HO-1 ${ }^{+/+}$control lung. (f) $\times 200 \mathrm{H} \& \mathrm{E}$ stain showing organized granuloma formation in $\mathrm{HO}-1^{+/+}$lung inoculated with $M$. avium for 6 months. $(\mathbf{g}) \times 200 \mathrm{H} \& \mathrm{E}$ stain of normal tissue from HO-1 - / - control lung. (h) $\times 200 \mathrm{H} \& \mathrm{E}$ stain of diffuse infection and dysfunctional granuloma formation in $\mathrm{HO}-1^{-1}$ lung inoculated with $M$. avium for 6 months. Five mice were included in each treatment group (lungs are not shown to scale).

Table 1 Granuloma formation and $M$. avium dissemination in $\mathrm{HO}-1^{-1-}$ and $\mathrm{HO}-1^{+/+}$mice

\begin{tabular}{lcc}
\hline Test/parameter & HO-1 $^{-1-}(\boldsymbol{n}=\mathbf{8})$ & HO-1 $^{+\prime+}(\boldsymbol{n}=\mathbf{8})$ \\
\hline Granuloma size & $29 \pm 10 \mu \mathrm{m}$ & $1100 \pm 102 \mu \mathrm{m}$ \\
Granuloma number & $3 \pm 1$ & $16 \pm 5$ \\
Morphometric index & $1 \pm 0.5$ & $10 \pm 0.2$ \\
$\begin{array}{l}\text { M. avium dissemination } \\
\text { (to liver, spleen) }\end{array}$ & Cultures positive & Cultures negative \\
Mortality & & \\
& $50 \%$ by 6 weeks & None by 6 weeks \\
\hline
\end{tabular}

(Table 1$)$. In $\mathrm{HO}-1^{+/+}$mice, there was no dissemination of infection. There was no mortality $(n=8)$ in this group even at 16 weeks following intratracheal infection of $M$. avium. In contrast, $\mathrm{HO}-1^{-1-}$ mice infected with $M$. avium had persistent infection in the liver and spleen at all-time points (Table 1). Notably, HO-1 ${ }^{-1-}$ mice that failed to form organized, mature granulomas, also had significantly higher average $M$. avium CFU counts in their lung tissue as compared with $\mathrm{HO}-1^{+1+}$ mice (Figure 6 ). It is possible that the increased mortality seen in the $\mathrm{HO}-1^{-1}$ is secondary to the dissemination of the organisms to other vital organs.

\section{MCP-1 Levels are Significantly Increased in BALF and Serum of HO-1 ${ }^{-I}$ Mice Following $M$. avium Infection} Since MCP-1 is the soluble ligand for CCR2, we analyzed the MCP-1 levels in BALF and serum samples from the
HO- $1^{+/+}$and $\mathrm{HO}-1^{-/-}$mice infected with $M$. avium or treated with saline. We observed a significant increase of MCP-1 levels in the BALF of infected HO- $1^{+/+}$mice as compared with non-infected controls, as well as increased levels in HO- $1^{-1-}$ M. avium infected mice as compared with HO- $1^{-/-}$non-infected controls (Figure 7a). Additionally, MCP-1 levels were higher in $\mathrm{HO}-1^{-/-}$control mice as compared with $\mathrm{HO}-1^{+1+}$ control mice. Similar results were found when we analyzed the MCP-1 levels in the corresponding serum samples. $\mathrm{HO}-1^{-/-}$mice infected with M. avium showed higher levels of the cytokine as compared with $\mathrm{HO}-1^{+/+}$samples (Figure $7 \mathrm{a}$ ). Furthermore, the levels of MCP-1 in sera of HO-1 $1^{-1}$ mice infected with $M$. avium were significantly higher than $\mathrm{HO}-1^{+/+}$and non-infected HO- $1^{-1}-$ mice (Figure 7a). Although the MCP-1 profile was the same between BALF and serum samples for each condition, the amount of MCP-1 was up to 1000-fold higher in BALF than serum.

\section{CCR2 Expression was Increased in PBMC of M. avium

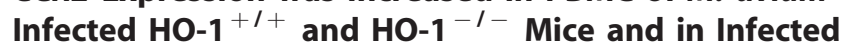 PAM of HO-1 ${ }^{-1-}$ Mice}

CCR2 expression was significantly higher in PAM from $M$. avium infected $\mathrm{HO}-1^{-1-}$ mice compared with $\mathrm{PAM}$ from M. avium infected $\mathrm{HO}-1^{+/+}$mice. In $\mathrm{HO}-1^{+/+}$mice infected with $M$. avium, the PBMC CCR2 expression was higher than compared with PAM CCR2 expression. These data demonstrate that in the absence of HO-1, CCR2 expression perpetuates a lack of retention of monocytemacrophages at the site of infection (Figure 7b). 

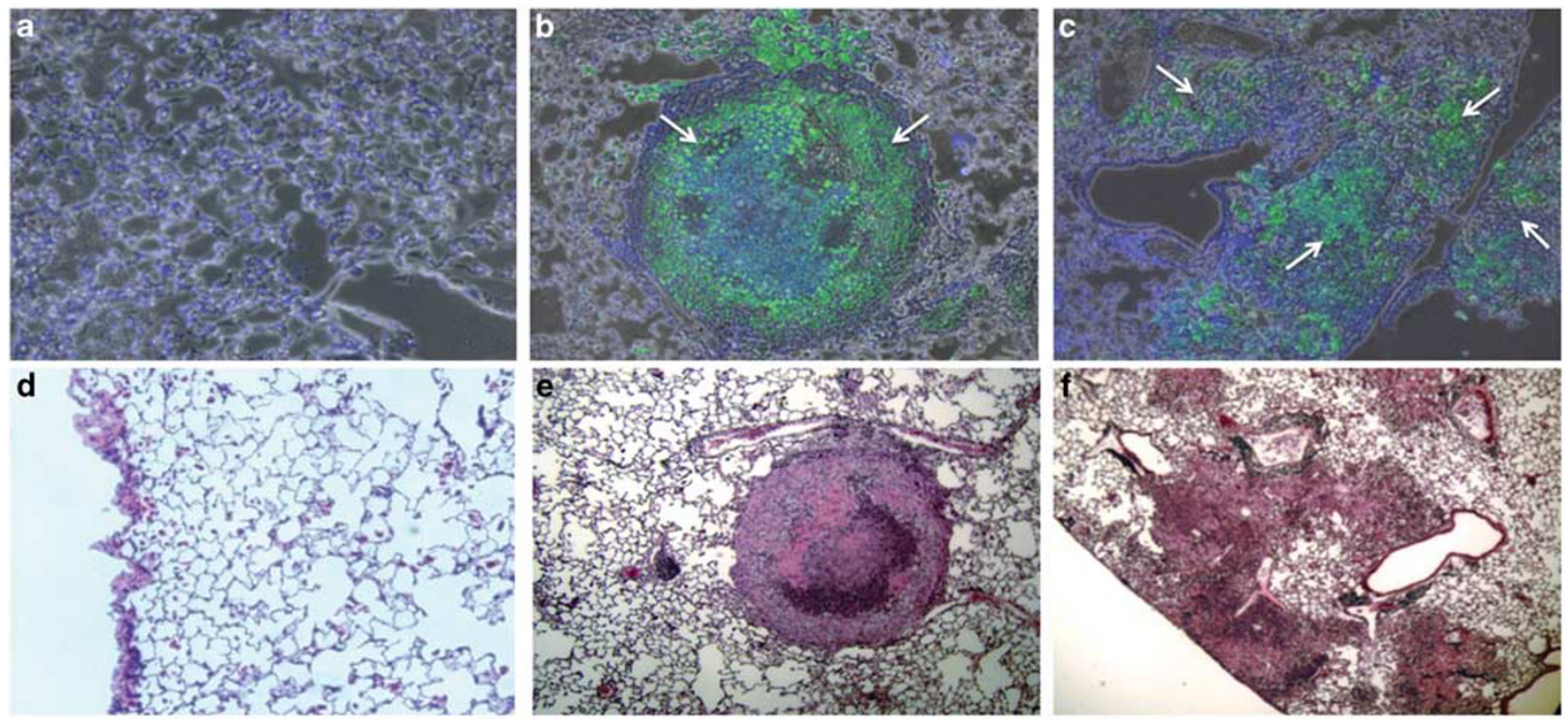

Figure $4 \mathrm{HO}-1^{-1-}$ mice showed diffuse $M$. avium infection in lung issue as opposed to $\mathrm{HO}-1^{+/+}$mice that contained the mycobacteria in mature, well-formed granulomas. The lung sections were stained with fluorescent auramine stain (BD Biosciences, Sparks, MD, USA) to show M. avium (green color) in lung tissue. (a) Auramine stain of $\mathrm{HO}_{-1}{ }^{+/+}$control lung. (b) Auramine stain of HO-1 ${ }^{+/+}$lung infected with M. avium for 6 months.

(c) Auramine stain of $\mathrm{HO}_{-1}^{-1-}$ lung after 6 months $M$. avium infection. White arrows show the presence of $M$. avium. (d-f) H\&E stain corresponding to panels $(\mathbf{a}-\mathbf{c})$.

\section{HO-1 Protein Levels Increase in Mouse Lung Tissue Following M. avium Infection}

In accordance with the HO-1 results found in RAW 264.7 cells treated with $M$. avium, we analyzed expression of this protein in the lung tissue of $\mathrm{HO}-1^{+/+}$and $\mathrm{HO}-1^{-1-}$ infected and non-infected mice. We detected that HO-1 was expressed and co-localized in granuloma in $\mathrm{HO}-1^{+/+}$lungs infected with $M$. avium as compared with non-infected mice (Figure $8 \mathrm{a}$ and $\mathrm{b}$ ). Furthermore, we stained lung tissue from HO- $1^{-1-}$ infected and non-infected mice to confirm that these mice did not express HO-1 (data not shown). Western blot analysis confirmed that HO-1 protein levels were upregulated in lung tissue from $M$. avium infected mice as opposed to uninfected controls (Figure 8c).

\section{CCR2 Co-Localizes to Granulomas in HO-1 ${ }^{+/+}$Infected Lung Tissue but not in HO-1 ${ }^{-I_{-}^{-}}$Infected Lung Tissue}

To confirm previous in vitro results that showed that HO-1 regulates the expression of CCR2, we examined CCR2 expression in the lung tissue of $\mathrm{HO}-1^{+/+}$and $\mathrm{HO}-1^{-1-}$ $M$. avium infected and non-infected mice. We observed that HO- $1^{-I-}$ non-infected mice had higher basal levels of CCR2 in lung tissue compared with $\mathrm{HO}-1^{+/+}$non-infected mice (Figure 9a and c). When we analyzed CCR2 levels in $M$. avium infected mice, we found that this receptor was upregulated and co-localized to the granulomas in the lung tissue from $\mathrm{HO}-1^{+1+}$ mice (Figure $9 \mathrm{~b}$ ). On the other hand, CCR2 expression in infected $\mathrm{HO}-1^{-1-}$ lung tissue showed a diffuse pattern of expression in agreement with loose collections of mononuclear cells that did not organize into granuloma (Figure 9d).

\section{DISCUSSION}

In this study, we tested the interaction and regulation of three proteins: HO-1, MCP-1, and CCR2 in the process of granuloma formation in a mouse model. HO-1, an inducible, cytoprotective protein has been implicated in many inflammatory diseases as well as mycobacterial infections. ${ }^{10}$ Our results demonstrated that $\mathrm{HO}-1$ plays a role in granuloma formation and maturation by regulating MCP-1 and CCR2 expression in mouse monocytes and therefore regulating the cellular recruitment of these immune cells from the periphery to the site of infection and injury. Our findings may also have substantial implications for understanding the role of $\mathrm{HO}-1$ in the control of M. tuberculosis infection.

Since the advent of HIV and the AIDS epidemic, NTM infections have become a major source of disease around the world. ${ }^{1,22-26}$ M. avium complex (MAC) infections have been on the rise in both immune competent patients as well as the immunocompromised. ${ }^{1}$ The formation of granuloma is a vital part of the body's immune defense against invading pathogens. After infection with $M$. avium, failure to develop organized granulomas results in the dissemination of the infection and greater injury to the host. ${ }^{6}$ The regulated recruitment of immune cells including monocyte-macrophages, $\mathrm{T}$ cells, dendritic cells, and $\mathrm{B}$ cells to the site of infection and injury is essential for the host to 

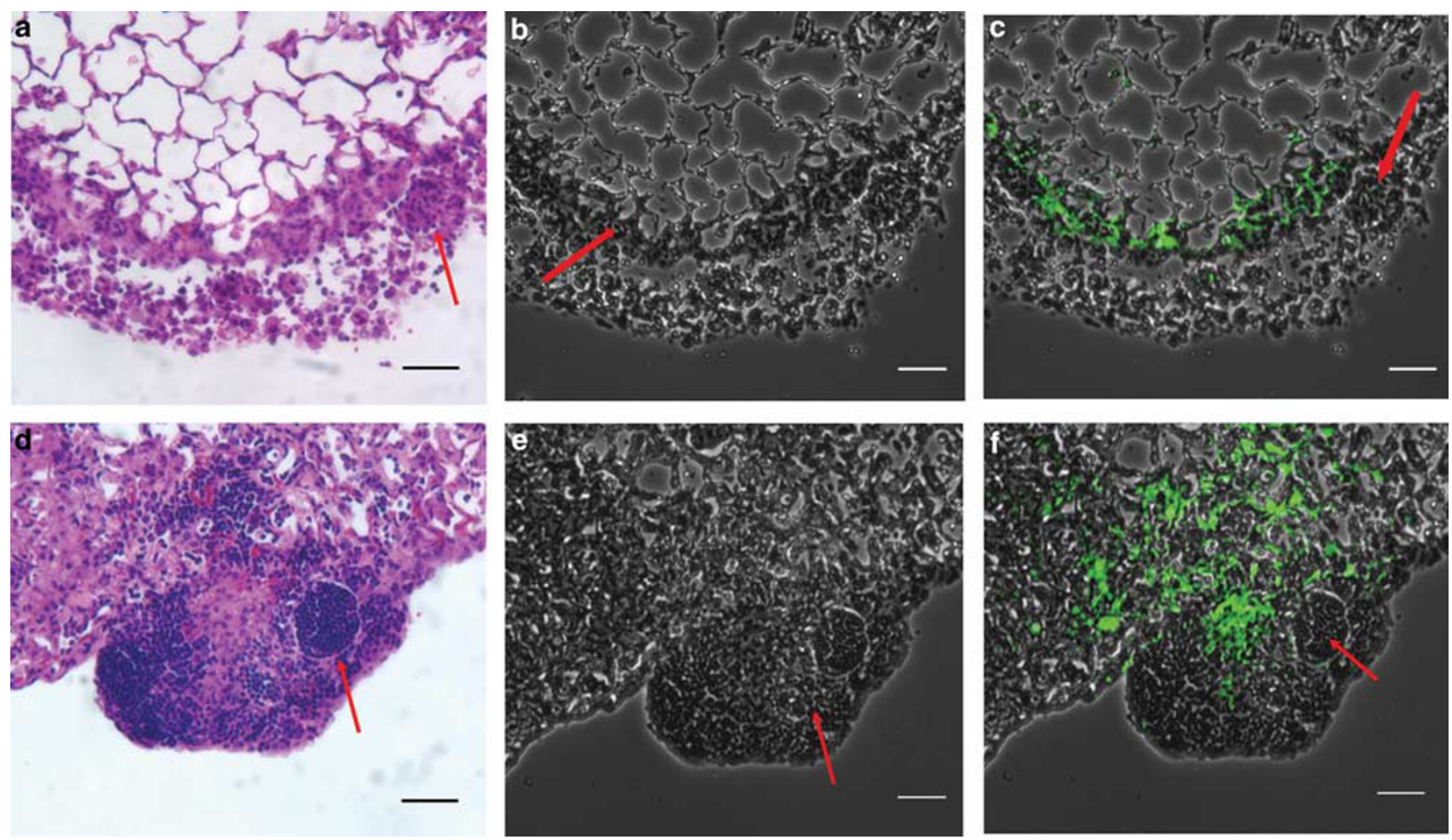

Figure 5 HO-1 modulates development and recruitment of monocytes recruitment into granuloma. $\mathrm{HO}-1^{-/-}$and $\mathrm{HO}-1^{+/+}$mice were infected with M. avium intratracheallyas described in Materials and methods. At 6 weeks, control and experimental mice were injected with PBMCs from GFP-positive mice. The mice were euthanized $24 \mathrm{~h}$ post-PBMC injection; the lungs were perfused with heparinised normal saline and fixed in $4 \%$ paraformaldehyde. The lungs were embedded in paraffin and $4 \mu \mathrm{m}$ sections were prepared, stained with $\mathrm{H} \& \mathrm{E}(\mathbf{a}, \mathbf{d})$. $\mathrm{HO}-1^{-1-}$ mice demonstrated poorly organized granuloma formation $(\mathbf{a}, \mathbf{b})$. The HO-1 ${ }^{+1+}$ mice demonstrated highly organized granuloma (d, e). The red arrows points to the granuloma. No organized granuloma formation was present in the HO-1 ${ }^{-1-}$ mice $(\mathbf{a}, \mathbf{b})$. This is a single representative image of H\&E-stained images of three mice from each strain. (c, f) The transmission microscopy images of pulmonary granulomas from $\mathrm{HO}-1^{-1-}$ and $\mathrm{HO}-1^{+/+}$mice, respectively. The HO-1-positive GFP-labeled monocytes given intravenously tracked into the granuloma of $\mathrm{HO}-1^{+/+}$mice (f) but they remain dispersed in $\mathrm{HO}-1^{-1-}$ mice (c). This is a single representative image of three similar images observed in six mice from each strain. The white arrows point to the granulomas. The green fluorescence indicated GFP-positive monocytes. Magnification $=\times 200$. Scale bar $=100 \mu \mathrm{m}$.

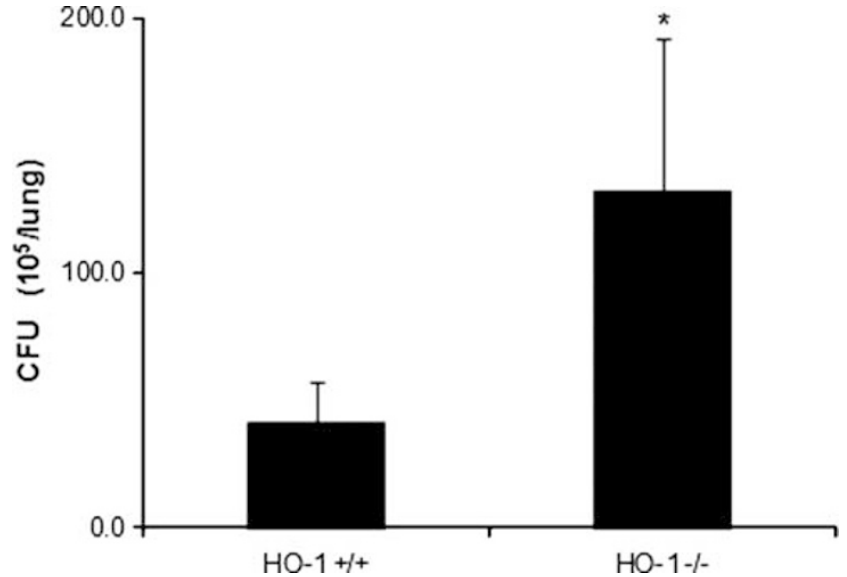

Figure 6 M. avium CFU counts are higher in lung tissue of infected HO- $1^{-1-}$ mice as compared with lung tissue form infected $\mathrm{HO}-1^{+1+}$ mice. Mouse lung tissue was homogenized in $2 \mathrm{ml}$ of $7 \mathrm{H} 9$ broth medium. Then, $100 \mu$ l of 10 -fold serial dilutions were plated on $7 \mathrm{H} 10$ agar plates and incubated for $10-21$ days in $37^{\circ} \mathrm{C}$ after which CFUs were counted. CFU counts were significantly higher $\left({ }^{*} P<0.05\right)$ in lung tissue of infected $\mathrm{HO}-1^{-1-}$ mice as compared with $\mathrm{HO}-1+/+$ mouse tissue. Values represent the average CFU counts from four mice in either non-infected or M. avium infected groups. contain and eliminate invading pathogens. ${ }^{27}$ In the course of granuloma maturation, the recruitment of phagocytes and lymphocytes is driven by various cytokines and chemokines that are initially produced by mycobacteria-infected macrophages. ${ }^{8}$

MCP-1 is the chemokine responsible for creating a gradient for the chemotaxis of immune cells from the periphery to the site of infection and CCR2 is the cell surface receptor which is bound by MCP-1. ${ }^{28} \mathrm{MCP}-1$ and CCR2 are both involved in the process of cellular recruitment to granuloma and in this study we demonstrate that HO-1 is a key regulator of these cytokines and therefore the immune recruitment process and granuloma formation.

From our in vitro experiment using RAW 264.7 mouse monocytes, we observed that HO-1 is induced by M. avium as early as $4 \mathrm{~h}$ post-treatment (data not shown) and stayed highly expressed up to $24 \mathrm{~h}$ (Figure 1). Once activated by M. avium, these monocytes begin to express higher levels of both MCP-1 (Figure 2a) and CCR2 (Figure 2b). However, when the cells were treated with ZnPP-IX, an inhibitor for $\mathrm{HO}$ enzyme activity, a decreased expression of MCP-1 and an increase in expression of CCR2 were observed, suggesting 

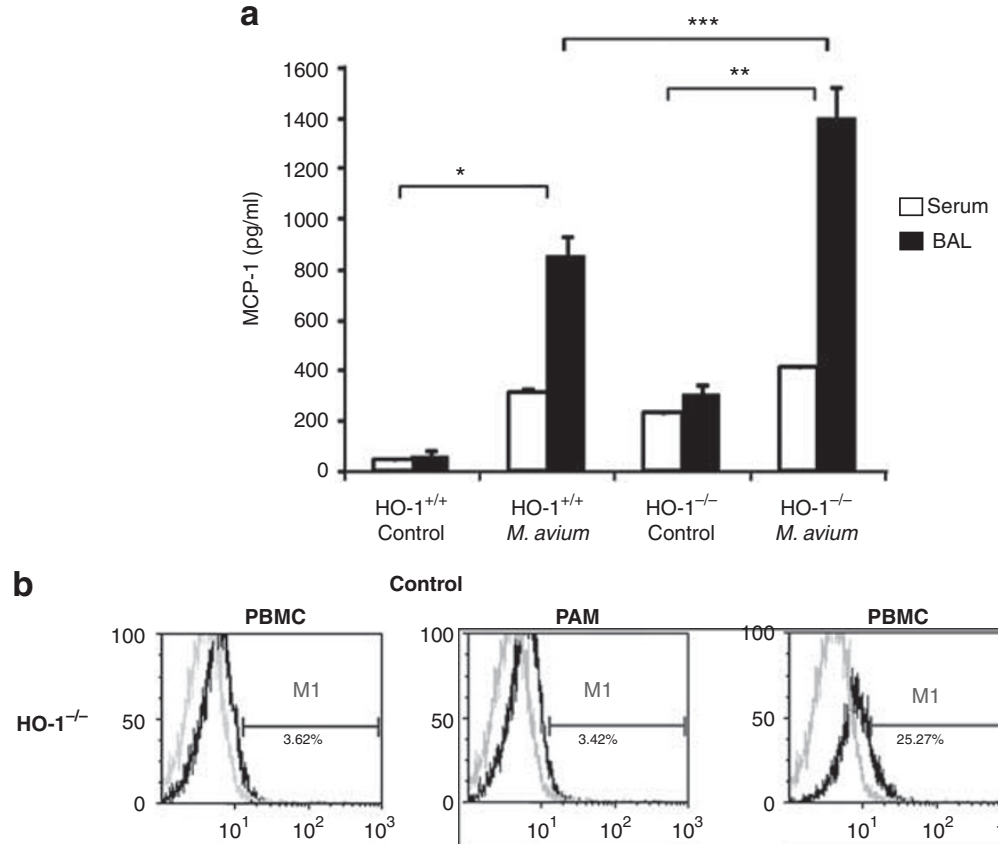

Control
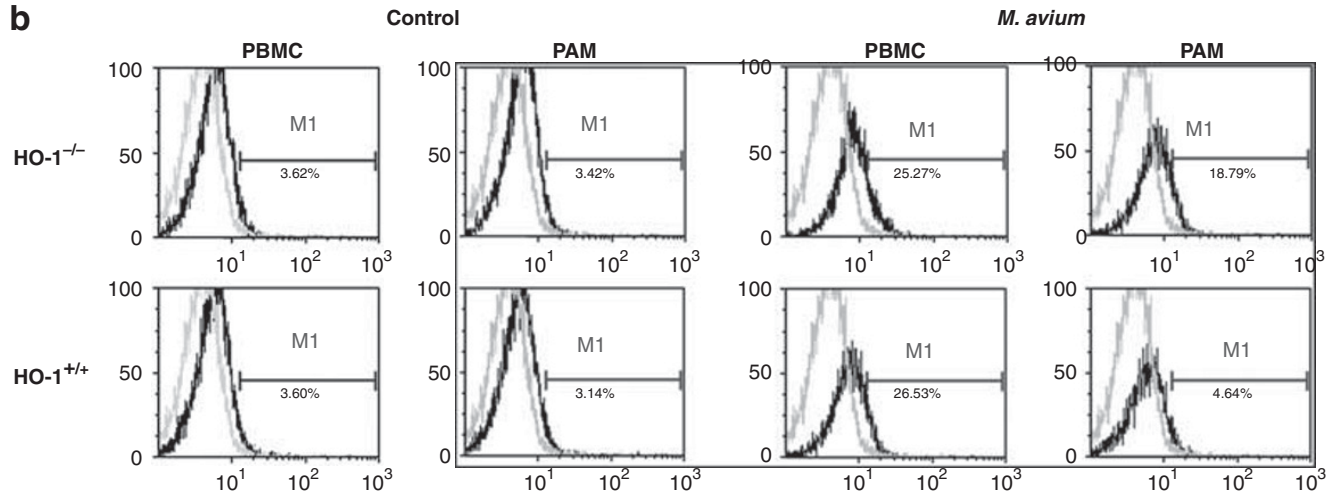

Figure 7 (a) MCP-1 levels are upregulated in BALF and serum samples of $M$. avium infected $\mathrm{HO}-1^{+/+}$and $\mathrm{HO}-1^{-/-}$mice. BALF and serum were collected and MCP-1 protein levels were measured by ELISA. MCP-1 levels were significantly increased in BALF of infected HO- $1^{+/+}$mice as compared with $\mathrm{HO}-1^{+/+}$saline controls $\left({ }^{*} P<0.001\right)$ and $\mathrm{HO}-1^{-/-}$mice as compared with $\mathrm{HO}-1^{-/-}$saline controls $(* * P<0.001)$. MCP-1 levels are increased in mouse serum after 6 months $M$. avium infection and are significantly higher in infected $\mathrm{HO}-1^{+1+}$ as compared with saline controls $\left({ }^{*} P<0.0001\right)$ and HO- $1^{-1-}$ mice $(* * P<0.0001)$ as compared with saline controls. MCP-1 levels were significantly higher in $M$. avium infected HO- $1^{-1-}$ mice then in M. avium infected $\mathrm{HO}-1^{+/+}$mice $\left({ }^{* *} P<0.05\right)$. Samples from five mice in each group were assayed in triplicate. (b) CCR2 expression in PBMC and PAM of $\mathrm{HO}-1^{+1+}$ and $\mathrm{HO}-1^{-1-}$ mice after M. avium infection. CCR2 receptor PAM in $\mathrm{HO}-1^{-1-}$ mice with $M$. avium infection is significantly increased compared with $M$. avium infected $\mathrm{HO}-1^{+/+}$mice. CCR2 expression in PBMC and PAM in $\mathrm{HO}-1^{-1-}$ mice with $M$. avium infection were comparable. This is a representative histogram of three experiments with similar observation. Control mice received saline.

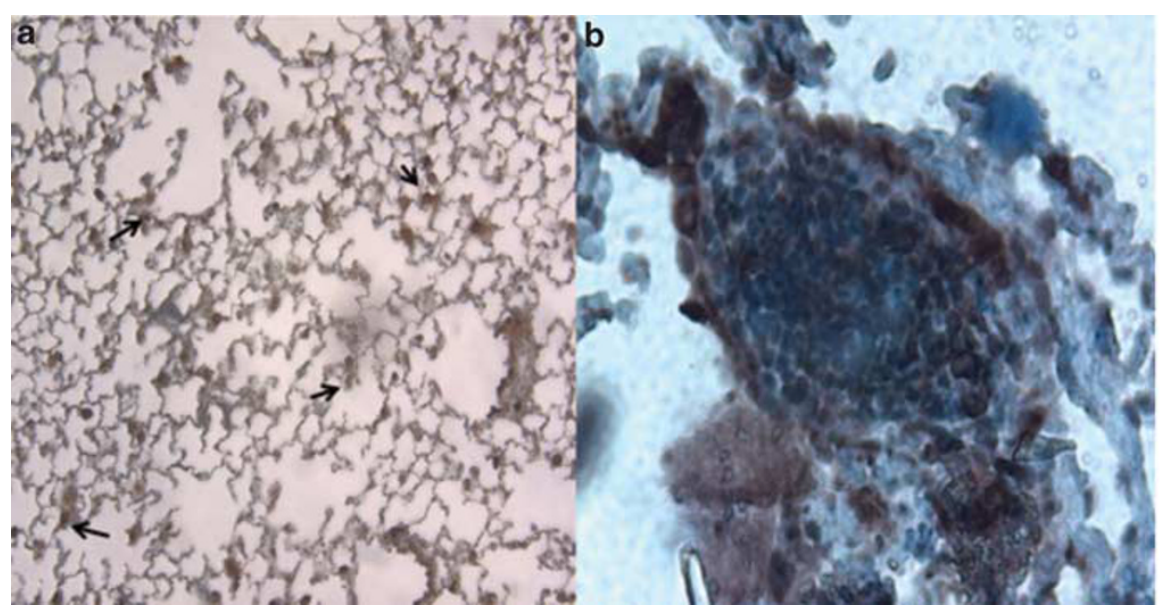

c

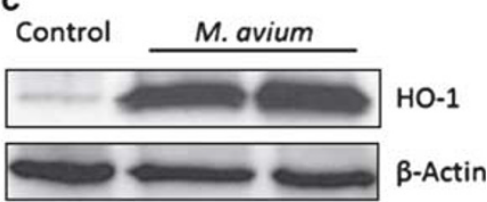

Figure 8 HO-1 protein expression is upregulated and co-localizes to granuloma after M. avium infection in mouse lung tissue. Paraffin fixed lung sections were stained using primary antibody against $\mathrm{HO}-1$. (a) HO-1 $1^{+1+}$ mouse lung showing basal levels of $\mathrm{HO}-1$ (brown) at $\times 100$ magnification. (b) $\mathrm{HO}-1^{+/+}$ M. avium infected mouse lung showing increased expression of HO-1 (brown) in granuloma at $\times 200$ magnification. Nuclei were counterstained with hematoxylin (blue). Experiments were done in triplicate. (c) HO-1 protein levels were assessed in lung tissue of saline control mice (lane 1) and $M$. avium infected mice (lanes 2 and 3) by western blot using primary antibody against HO-1. $\beta$-Actin was probed as an internal loading control. Blotted antibody was developed by horseradish peroxidase-conjugated secondary antibody and enhanced chemiluminescence detection system. 

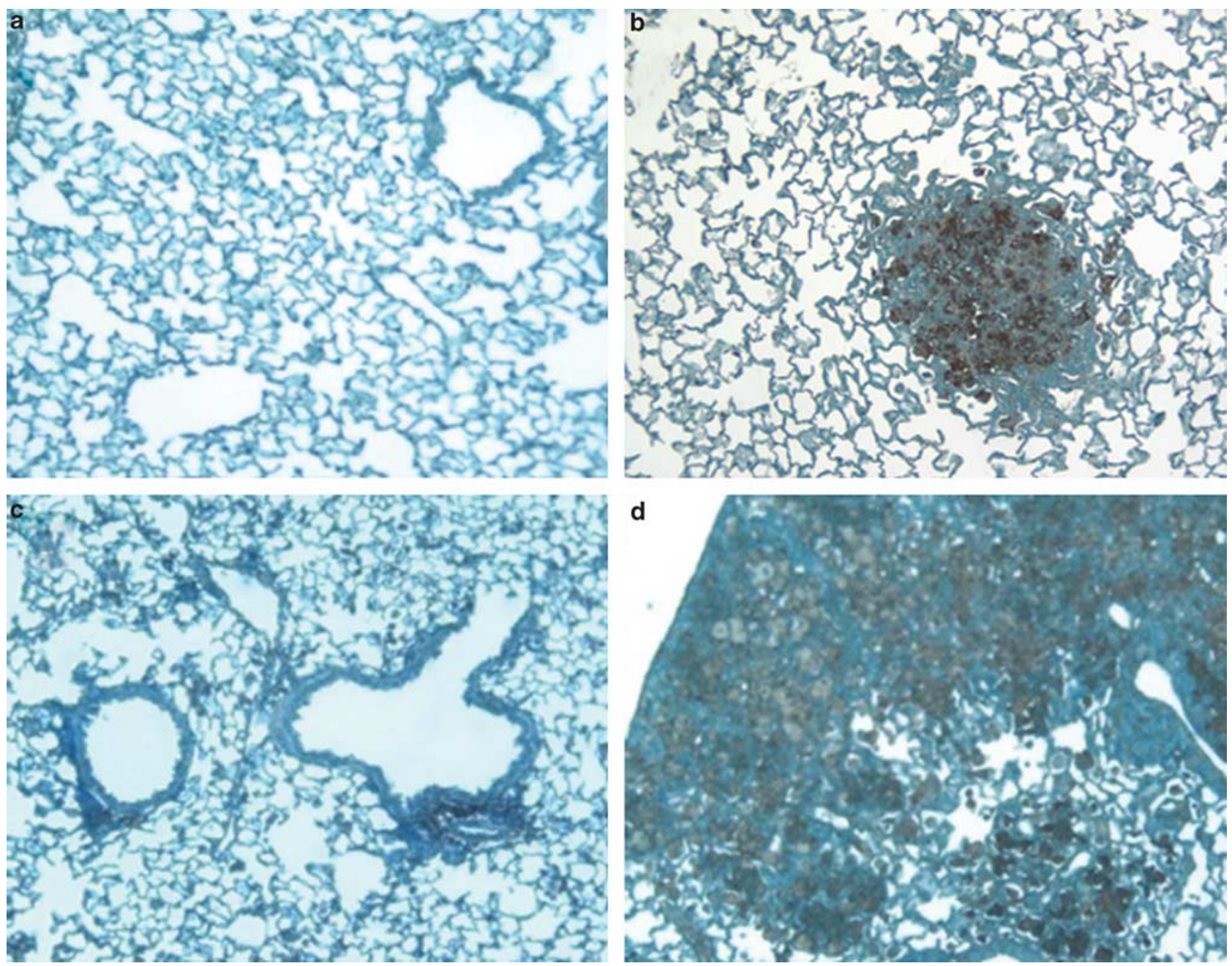

Figure 9 CCR2 co-localizes to granuloma in $\mathrm{HO}-1^{+/+}$mouse lung tissue but shows a diffuse pattern of expression in $\mathrm{HO}-1^{-/-}$mouse lungs following M. avium infection. Lung sections were stained for CCR2 receptor using anti-CCR2 antibody. (a) HO-1+1+ lung tissue from saline inoculated mouse showing basal levels of CCR2 (brown). (b) HO-1 ${ }^{+1+}$ lung tissue from mouse inoculated with M. avium for 6 months. CCR2 (brown) expression was upregulated and co-localized to granuloma. (c) $\mathrm{HO}-1^{-1-}$ saline inoculated mouse lung section showing basal levels of CCR2 expression (brown). (d) Increased and diffuse CCR2 expression in $\mathrm{HO}-1^{-1}$ mouse lung tissue following 6 months $M$. avium infection. Blue color shows counter-stain with hematoxylin. All pictures were taken at a magnification of $\times 100$. Lungs were harvested from five mice in each treatment group.

that HO-1 levels are directly correlated with MCP-1 expression and inversely correlated with CCR2 expression.

Previous studies suggest conflicting evidence in terms of the correlation between HO-1, MCP-1, and CCR2. MCP-1 was shown to be downregulated at both mRNA and protein level with the inhibition of HO-1. ${ }^{29-31}$ Zampetaki et al $b^{32}$ showed that despite high mRNA levels, significantly lower levels of cytokine protein were found in BALF of mice overexpressing HO-1. These findings suggest that HO-1 overexpression can suppress the induction of cytokine mRNA levels. Our in vitro and in vivo results, however, demonstrate that inhibiting $\mathrm{HO}$ enzyme activity led to altered MCP-1 protein levels in BALF and serum (Figure 7a), suggesting that $\mathrm{HO}-1$ directly regulates MCP-1 expression in mouse monocytes. Since we observed an induction of HO-1 and increased levels of MCP-1 in the lung tissue, BALF and serum of infected $\mathrm{HO}-1^{+/+}$mice, it is possible that an MCP-1 gradient was established in order to recruit monocytes from the peripheral blood to the lung. This corresponds to a normal immune response in which cells expressing CCR2 are recruited from the periphery and move along an MCP-1 gradient towards the site of infection in order to from granulomas. ${ }^{13}$

This phenomenon of regulated expression of CCR2 is abnormal in $\mathrm{HO}-1^{-1-}$ mice. However, in spite of high MCP-1 levels in the lung, there is poor recruitment of monocytes to the granuloma in the lung parenchyma. CCR expression, the other critical component of the ligandreceptor interaction is affected since we found that in $\mathrm{HO}-1^{-1-}$ mice CCR2 was not downregulated in the PAM. When testing MCP-1 protein levels in infected mice, we observed higher basal levels of MCP-1 in sera and BALF in 
control HO-1 ${ }^{-1-}$ mice as compared with wild-type controls (Figure 7a). These results support previous findings ${ }^{19,32-34}$ and suggest that $\mathrm{HO}-1^{-1-}$ mice are in a chronic state of inflammation. This chronic inflammatory state could lead to the dysregulation of the MCP-1 chemotactic gradient, which would then disrupt cellular recruitment to the site of granuloma.

Previous findings along with our results suggest that different cell types in various organ systems may react differently to altered levels of HO-1. This may be due to direct regulation by $\mathrm{HO}-1$ on $\mathrm{MCP}-1$ gene expression via the $\mathrm{NF} \kappa \mathrm{B}$ signaling pathway. Jadhav et al ${ }^{35}$ have shown that HO-1 and more specifically, hemin therapy, can reduce $\mathrm{NF} \kappa \mathrm{B}$ mRNA levels by $87.1 \%$, which would therefore lead to a reduction in cytokine production. It has been reported that when HO-1 enzymatic activity is inhibited by ZnPP-IX, the levels of CCR2 increase, ${ }^{36,37}$ suggesting that $\mathrm{HO}-1$ regulates the expression of CCR2 on the surface of monocytes, macrophages and other immune cells. Our results show that $\mathrm{HO}-1^{-1-}$ mice had increased levels of CCR2 on monocyte/macrophage cell surfaces as seen by relative gene expression (Figure 2b) and immunohistochemistry (Figure 9). Other studies ${ }^{38-40}$ suggest that the lack of HO-1 causes a pro apoptotic milieu, which leads to loss of an adequate monocyte-macrophage that can lead to decreased granuloma formation.

Our findings also suggest that HO- 1 normally regulates the expression of the CCR2 during infection and allows directed migration of monocyte-macrophages along an MCP-1 gradient towards the organism. When we analyzed the results from our in vivo mouse model, we observed that the loss of HO-1 expression led to loose or unorganized collections of mononuclear cells in mice following $M$. avium infection. HO- $1^{-I-}$ mice failed to form mature, organized granulomas and this led to diffuse inflammation throughout the lungs and to dissemination of the infection to the liver and spleen. The significant increase of MCP-1 in the BALF of HO- $1^{-1-}$ mice (Figure 7a) following M. avium infection may lead to increased or unregulated recruitment of CCR2 expressing cells into the lung parenchyma and could also explain the diffuse, widespread inflammation in the lung tissue of these mice. These factors taken together could explain why these mice failed to form mature granulomas and therefore, failed to contain the infection. An increase in CFU was also observed in the lung issue of $\mathrm{HO}-1^{-1-}$ mice as compared with HO- $1^{+1+}$ mice following $M$. avium infection (Figure 6). It is possible that the increased numbers of organisms combined with the dissemination to other vital organs contribute to the increased mortality in these mice. Based on these results, it seems that $\mathrm{HO}-1$ plays a critical role in the regulation of cellular recruitment to the site of infection and in organized granuloma formation following infection with M. avium.

HO-1 is recognized to affect not just host responses but also mycobacterial expression of specific genes. $\mathrm{CO}$ a breakdown product of heme metabolism causes mycobacteria to express the dormancy (Dos) regulon. ${ }^{13}$

In conclusion, HO-1 is not only involved, but plays an essential role in the processes involved in cellular recruitment of monocytes from the peripheral blood to the sites of infection with mycobacteria. It is possible that other diseases in which granuloma formation is a vital host defense response, HO-1 may play a regulatory role in the response. The HO- $1^{-1-}$ mouse model provides a useful tool in the study of granuloma formation following $M$. avium infection. Our findings further substantiate the role of $\mathrm{HO}-1$ in the regulation of MCP-1 and CCR2 and its key involvement in innate and adaptive immune responses following M. avium infection.

\section{ACKNOWLEDGEMENTS}

We thank Barbara N Locke CVT, LATG for her technical assistance and veterinary expertise. We also thank Edward C Hensel RN for his assistance. This work was supported by NIH RO1 Al080349 and R21 AA 014796 to VBA. We acknowledge the O'Brien center (1P30 DK079337 to AA) at the University of Alabama at Birmingham for their support and helpful discussions.

\section{DISCLOSURE/CONFLICT OF INTEREST}

The authors declare no conflict of interest.

1. Falkinham 3rd JO. Epidemiology of infection by nontuberculous mycobacteria. Clin Microbiol Rev 1996;9:177-215.

2. Falkinham 3rd JO. Surrounded by mycobacteria: nontuberculous mycobacteria in the human environment. J Appl Microbiol 2009;107: 356-367.

3. Horsburgh CR, Nelson AM. Mycobacterium avium. In: Pathology of Emerging Infections-2. Nelson AM, Horsburgh CR (eds). American Society for Microbiology: Washington, 1998, pp 193-216.

4. Kahana LM, Kay JM, Yakrus MA, et al. Mycobacterium avium complex infection in an immunocompetent young adult related to hot tub exposure. Chest 1997;111:242-245.

5. Ahn $\mathrm{CH}$, Lowell JR, Onstad GD, et al. A demographic study of disease due to Mycobacterium kansasii or $\mathbf{M}$ intracellulare-avium in Texas. Chest 1979;75:120-125.

6. Hendricks $\mathrm{EE}$, Lin $\mathrm{KC}$, Boisvert $\mathrm{K}$, et al. Alterations in expression of monocyte chemotactic protein-1 in the simian immunodeficiency virus model of disseminated Mycobacterium avium complex. J Infect Dis 2004;189:1714-1720.

7. Inderlied $\mathrm{CB}$, Kemper CA, Bermudez LE. The Mycobacterium avium complex. Clin Microbiol Rev 1993;6:266-310.

8. Okamoto Yoshida Y, Umemura M, Yahagi A, et al. Essential role of IL$17 \mathrm{~A}$ in the formation of a mycobacterial infection-induced granuloma in the lung. J Immunol 2010;184:4414-4422.

9. Benini J, Ehlers EM, Ehlers S. Different types of pulmonary granuloma necrosis in immunocompetent vs. TNFRp55-gene-deficient mice aerogenically infected with highly virulent Mycobacterium avium. J Pathol 1999;189:127-137.

10. Fredenburgh LE, Perrella MA, Mitsialis SA. The role of heme oxygenase-1 in pulmonary disease. Am J Respir Cell Mol Biol 2007;36: 158-165.

11. Mizuno K, Toma T, Tsukiji $\mathrm{H}$, et al. Selective expansion of CD16highCCR2- subpopulation of circulating monocytes with preferential production of haem oxygenase (HO)-1 in response to acute inflammation. Clin Exp Immunol 2005;142:461-470.

12. Nath KA. Heme oxygenase-1: a provenance for cytoprotective pathways in the kidney and other tissues. Kidney Int 2006;70:432-443.

13. Kumar A, Deshane JS, Crossman DK, et al. Heme oxygenase-1-derived carbon monoxide induces the Mycobacterium tuberculosis dormancy regulon. J Biol Chem 2008;283:18032-18039. 
14. Lundien MC. Mohammed KA. Nasreen N, et al. Induction of MCP-1 expression in airway epithelial cells: role of CCR2 receptor in airway epithelial injury. J Clin Immunol 2002;22:144-152.

15. Nasreen N, Mohammed KA, Galffy G, et al. MCP-1 in pleural injury: CCR2 mediates haptotaxis of pleural mesothelial cells. Am J Physiol Lung Cell Mol Physiol 2000;278:L591-L598.

16. Ma Y, Ren S, Pandak WM, et al. The effects of inflammatory cytokines on steroidogenic acute regulatory protein expression in macrophages. Inflamm Res 2007;56:495-501.

17. Nasreen N, Mohammed KA, Mubarak KK, et al. Pleural mesothelial cell transformation into myofibroblasts and haptotactic migration in response to TGF-beta1 in vitro. Am J Physiol Lung Cell Mol Physiol 2009;297:L115-L124.

18. Lean JM, Murphy C, Fuller K, et al. CCL9/MIP-1gamma and its receptor CCR1 are the major chemokine ligand/receptor species expressed by osteoclasts. J Cell Biochem 2002;87:386-393.

19. Poss KD, Tonegawa $\mathrm{S}$. Heme oxygenase 1 is required for mammalian iron reutilization. Proc Natl Acad Sci USA 1997:94:10919-10924.

20. Kapturczak MH, Wasserfall C, Brusko T, et al. Heme oxygenasemodulates early inflammatory responses: evidence from the heme oxygenase-1-deficient mouse. Am J Pathol 2004;165:1045-1053.

21. Montes-Worboys A, Brown S, Regev D, et al. Targeted delivery of amikacin into granuloma. Am J Respir Crit Care Med 2010;182 1546-1553.

22. Horsburgh Jr CR. Mycobacterium avium complex infection in the acquired immunodeficiency syndrome. N Engl J Med 1991;324: 1332-1338.

23. Horsburgh Jr CR. Epidemiology of mycobacterial diseases in AIDS. Res Microbiol 1992;143:372-377.

24. Horsburgh Jr CR, Selik RM. The epidemiology of disseminated nontuberculous mycobacterial infection in the acquired immunodeficiency syndrome (AIDS). Am Rev Respir Dis 1989;139:4-7.

25. Peters $M$, Schurmann $D$, Mayr $A C$, et al. Immunosuppression and mycobacteria other than Mycobacterium tuberculosis: results from patients with and without HIV infection. Epidemiol Infect 1989;103: 293-300.

26. Selik RM, Starcher ET, Curran JW. Opportunistic diseases reported in AIDS patients: frequencies, associations, and trends. Aids 1987;1: 175-182.

27. Ehlers $S$, Kutsch $S$, Ehlers EM, et al. Lethal granuloma disintegration in mycobacteria-infected TNFRp55 - / - mice is dependent on T cells and IL-12. J Immunol 2000;165:483-492.
28. Huffnagle GB, Strieter RM, Standiford TJ, et al. The role of monocyte chemotactic protein-1 (MCP-1) in the recruitment of monocytes and CD4 $+\mathrm{T}$ cells during a pulmonary Cryptococcus neoformans infection. J Immunol 1995;155:4790-4797.

29. Jiang $\mathrm{Y}$, Valente AJ, Williamson $\mathrm{MJ}$, et al. Post-translational modification of a monocyte-specific chemoattractant synthesized by glioma, osteosarcoma, and vascular smooth muscle cells. J Biol Chem 1990;265:18318-18321.

30. Lee JS, Lee JY, Son JW, et al. Expression and regulation of the CC chemokine ligand 20 during human tuberculosis. Scand J Immunol 2008;67:77-85.

31. Pittock ST, Norby SM, Grande JP, et al. MCP-1 is up-regulated in unstressed and stressed HO-1 knockout mice: Pathophysiologic correlates. Kidney Int 2005;68:611-622.

32. Zampetaki A, Minamino T, Mitsialis SA, et al. Effect of heme oxygenase-1 overexpression in two models of lung inflammation. Exp Biol Med (Maywood) 2003;228:442-446.

33. Yachie A, Niida $Y$, Wada $T$, et al. Oxidative stress causes enhanced endothelial cell injury in human heme oxygenase-1 deficiency. J Clin Invest 1999;103:129-135.

34. Poss KD, Tonegawa S. Reduced stress defense in heme oxygenase 1deficient cells. Proc Natl Acad Sci USA 1997;94:10925-10930.

35. Jadhav A, Torlakovic E, Ndisang JF. Interaction among heme oxygenase, nuclear factor-kappaB, and transcription activating factors in cardiac hypertrophy in hypertension. Hypertension 2008;52:910-917.

36. Kanakiriya SK, Croatt AJ, Haggard JJ, et al. Heme: a novel inducer of MCP-1 through HO-dependent and HO-independent mechanisms. Am J Physiol Renal Physiol 2003;284:F546-F554.

37. Morita T, Imai T, Yamaguchi T, et al. Induction of heme oxygenase-1 in monocytes suppresses angiotensin II-elicited chemotactic activity through inhibition of CCR2: role of bilirubin and carbon monoxide generated by the enzyme. Antioxid Redox Signal 2003;5:439-447.

38. Al-Owais MM, Scragg JL, Dallas ML, et al. Carbon monoxide mediates the anti-apoptotic effects of heme oxygenase- 1 in medulloblastoma DAOY cells via K + channel inhibition. J Biol Chem 2012;287:2475424764.

39. Rushworth SA, MacEwan DJ. HO-1 underlies resistance of AML cells to TNF-induced apoptosis. Blood 2008;111:3793-3801.

40. Babu D, Soenen SJ, Raemdonck K, et al. TNF-alpha/cycloheximideinduced oxidative stress and apoptosis in murine intestinal epithelial MODE-K cells. Current Pharmaceutical Design, advance online publication, 23 June 2012 (in press). 